\title{
Specific Learning Disabilities: The changing scenario
}

\author{
Prasad Aishwarya
}

'Specific Learning disabilities' hasn't always been a household term. We only began to discover the reasons for learning problems a little over a century ago, and in many countries people still have to understand the basic rights regarding equal opportunities and appropriate education. A learning disability, or learning disorder, is not a problem with intelligence. They are caused by a difference in the brain that affects how information is received, processed, or communicated. Children and adults with learning disabilities have trouble processing sensory information because they see, hear, and understand things differently.

It first came into light in 1877 when German neurologist Adolf Kussamaul coined the term "word blindness" to describe "complete text blindness, although the power of sight, the intellect and the powers of speech are intact."

Around $5 \%$ of the world population suffers from Learning Disabilities. According to the National Health Information Survey of 1997, 4.6 million children are believed to be suffering with learning disabilities in the world. 18,012,222 people are currently believed to be suffering with specific learning disabilities in India alone.

Learning disabilities can be overcome if detected at an appropriate time. The need today is early diagnosis and a proper understanding of the etiologic factors to tackle this problem. But how would we be able to deal with it when even today most people are ignorant about the high probability and incidence of specific learning disabilities.

According to one definition, a specific learning disability is a disorder in one or more of the central nervous system processes involved in perceiving, understanding and/or using concepts through verbal (spoken or written) language or nonverbal means.[1]

Researchers say that the presence of early risk factors does not conclusively cause a child to have learning disabilities, but it indicates a need to monitor for early intervention needs.

Few of the factors that may have an effect on the development of specific learning disabilities include: ${ }^{\text {at }}$

\section{- Family history of learning disabilities;}

- Injuries and long-term illnesses affecting neurological development;

- Parental substance abuse;

- Poor prenatal medical care and nutrition; Prenatal injury or delivery complications;

- Exposure to environmental toxins such as lead or toxic mold

Although many studies have not been undertaken, according to some, developmental delays in gross motor, fine motor, communication or cognitive skills may suggest a potential for specific learning disabilities. But we do need to keep in mind that mild differences in development among children are normal.

Specific learning disabilities usually come into light when the child reaches standard three, although in certain cases, if the child has a high IQ, it may be delayed. A child not suffering with any specific learning disability will be able to connect letters and sounds, read grade-level text, understand what he reads, understand number concepts, and will have no difficulty following directions or communicating with peers and adults. She/he usually also has no difficulty with attention or behavior. On the other hand, a child having a specific leaning disability will have difficulty in most of the above mentioned activities. "

\section{Common Types of Learning Disabilities}

Dyslexia Difficulty processing language Problems reading, comprehension, speaking

Dyscalculia Difficulty with math Problems doing math problems, understanding time, using money

Dysgraphia Difficulty with writing Problems with handwriting, spelling, organizing ideas

Learning disabilities are often identified by school teachers, clinical psychologists and psychiatrists, and neuropsychologists through a combination of intelligence testing, academic achievement testing, classroom

Eastern J. Psychiatry Vol. 14, No. 1-2 
performance, and social interaction and aptitude. The resulting information is used to determine whether a child's academic performance is commensurate with his or her cognitive ability. If a child's cognitive ability is much higher than his or her academic performance, the student is often diagnosed with a learning disability. This is known as the discrepancy model.

There are many treatment and intervention techniques presently in use to help people with specific learning disabilities. Poor academic achievement can be addressed with targeted interventions such as adjustments, equipment and assistants designed to help compensate for the disabilities or intended to make improvements in the weak areas. Practice is a particularly important.

Sternberg ${ }^{\text {s }}$ has studied in his research paper that early remediation can greatly reduce the number of children meeting diagnostic criteria for learning disabilities. Certain studies indicate that emphasis should be placed on the development of specific learning skills along with study and basic skills.

There exists amongst some researchers a criticism of the concept of learning disabilities. They believe that every child has a different learning style and pace and that each child is unique, not only capable of learning but also capable of succeeding. These critics assert that applying the medical model of problemsolving to individual children who are pupils in the school system, and labeling these children as disabled, systematically prevents the improvement of the current educational system. They believe that it's the current system followed at educational institutions which is at fault. Proponents of unschooling have also claimed that children raised in this method do not suffer from learning disabilities.

In India, the Leaning Disability movement is only a decade or two old. We lag behind the western world in this regard by around 50 years. During the last decade, the movement has definitely picked up momentum and more and more children with Specific Learning Disability are being identified. There is still a paucity of epidemiological studies conducted in India to determine the exact prevalence of scholastic backwardness, in general, and Specific Learning Disability (SLD), in particular. ${ }^{\circ 9}$

Its high time, we understood the concept of specific learning disabilities and incorporate it as an essential component of our health system.

\section{BIBLIOGRAPHY:}

1. 1997 Conference Proceedings of 'Center on Disabilities Technology and Persons with Disabilities' conference of California State University, Northridge. Information taken from their website www.csun.gov.in, accessed on 17th January, 2009.

2. Ann Longsdon, about.com. Top 8 signs to recognize early signs of learning disabilities, taken from their website accessed on 17th January, 2009. http://learningdisabilities.about.com/od/ learningdisabilitybasics/tp/SignsofLD.htm

3. Norberto Alvarez, MD, Assistant Professor, Department of Neurology, Harvard Medical School; Consulting Staff, Department of Neurology, Boston Children's Hospital. Movement Disorders in Individuals with Developmental Disabilities Article in the website http://emedicine.medscape.com/article/ 1153227-overview, accessed on 18th January, 2009.

4. Boetsch, E., Green, P. \& Pennington, B. (1996). Psychosocial correlates of dyslexia across the life span. Development \& Psychopathology, 8(3), 539562.

5. Sternberg, R. J., \& Grigorenko, E. L. (1999). Our labeled children: What every parent and teacher needs to know about learning disabilities. Reading, MA: Perseus Publishing Group

6. Cusimano, Addie (2001). Learning Disabilities: There is a Cure, Achieve Publications.

7. Greenberg, D. (1992), Education in America, A View from Sudbury Valley, "Special

Education" - A noble Cause Sacrificed to Standardization.

8. Greenberg, D. (1987), Free at Last, The Sudbury Valley School, Chapter 1, And 'Rithmetic.

9. Karanth, P. \& P.Prakash (2007)“A Developmental Investigation of onset, progress and stages of literary acquisition- Its implications for Instructional Process' New Delhi, NCERT.

Aishwarya Prasad,

Intern, T.N. Medical College,

Mumbai

aishwaryaprasad@gmail.com 